\title{
THE EFFECT OF FETAL CALF SERUM ON HUMAN DENTAL PULP STEM CELLS
}

\author{
Jakub Suchánek ${ }^{1}$, Tereza Suchánková Kleplová1, Martin Kapitán', Tomášs Soukup²
}

Charles University in Prague, Faculty of Medicine in Hradec Králové, Czech Republic: Department of Dentistry¹; Department of Histology and Embryology2

Summary: Aims: Authors studied potential side effects of fetal calf serum (FCS) in cultivation media on human dental pulp stem cells (DPSC) during long term cultivation. Methods: Two lines of DPSC obtained healthy donors (male 22 years, female 23 years) were used. Both lines were cultivated under standard cultivation conditions in four different media containing $10 \%$ or $2 \%$ FCS and substituted with growth factors. During long term cultivation proliferation ability, karyotype and phenotype of DPSC were measured. Results: Both lines of DPSC cultivated in a media containing $2 \%$ FCS and ITS supplement showed the highest number of population doublings. On the other hand the proliferation rate of DPSC cultivated in a media with 2\% FCS without ITS supplement was slowest. Proliferation rate of DPSC cultivated in $10 \%$ FCS media with or without FGF-2 was comparable. DPSC cultivated in a media with $10 \%$ FCS showed a significantly higher amount of chromosomal aberrations. These chromosomal aberrations do not seem to be clonal but surprisingly we found large amounts of tetraploid cells in the 9th passage in both media containing $10 \%$ FCS. Conclusions: Our study proved that cultivation of DPSC in media containing higher concentration of FCS has critical side effects on cell chromosomal stability.

Key words: Dental pulp stem cells; Karyotype; Fetal calf serum

\section{Introduction}

Multipotent mesenchymal stromal stem cells (MSC) are defined as cells which are able to selfrenew or differentiate into other mature cell types (at last into adipocytes, chondrocytes and ostoblasts). These cells are moreover able to adhere to plastic surface of the cultivation flasks, are supposed to be positive at least for CD105, CD73, CD90 and have imunosupressive abilities and can undergo gene modification. MSC can be found in many different tissues in the multicellular organism during the whole lifetime (1-15). Their main function in the body is to create specialized cell types and maintain an unchanged line for future repair processes, which is why the stem cells can undergo asymmetric division. In contrast with embryonic stem cells, isolation of MSC does not provoke any ethical issues. For these reasons, these cells promised to be a good source for tissue engineering and gene therapy.

We can find many different articles describing properties of MSC, but the main question is: How does the cultivation medium affect the MSC during the long term cultivation?

Nowadays many scientists are focused on finding optimal cultivation media for MSC. Their main goal is to find animal free component media, which will not force MSC to differentiate or to change any of their properties like phenotype or differentiation potential and keeps high proliferation ability (16). There is no question that different types of cells need different approaches during the cultivation. For example, using fetal calf serum (FCS) can enhance the activity of glycerolphosphate dehydrogenase in adipocyte precursors and cause their differentiation (17). Expansion and proliferation of neural progenitors is reduced when cultured in FCS with N2 and without cytokines (18). On the other hand, FCS contains high levels of growth stimulatory factors and keeps lines in high proliferation activity without adding supplementary growth factors (19).

Since the year 2000 where the dental pulp stem cells (DPSC) were isolated from the dental pulp (9), these cells begin to be intensively studied. Their main advantage is relatively easy accessible source and the simplicity of isolation.

In the last 3 years some new approaches were established for isolation and cultivation of human dental pulp stem cells (DPSC). Recently described the way how to isolate the dental pulp from non-extracted tooth (20) and the protocol of imunomagnetic separation during DPSC isolation was established (21). Scientists have started to work on animal component free medium for DPSC (22) because using of animal components during cultivation prohibits clinical trials of SC in human medicine.

The most widely used animal component during the long term cultivation is FCS. Its amount in cultivation media varied from $2-20 \%$. The problem is that FCS is not 
a standardized supplement and the composition of each batch can vary slightly. Moreover it can be the source of different contamination which can cause allergic reactions or infectious diseases like bovine disease transmitted by prions and other zoonosis.

In this study we have focused on finding how the FCS can affect DPSC (e.g. karyotype, phenotype, proliferation ability) and which supplements could be used in the case of decreasing amount of FCS.

\section{Materials and methods}

\section{Isolation}

We isolated two different lines of DPSC, both from semierupted third molars. The first line marked DPSC ${ }_{1}$ was obtained from a 23 year old female, the second line $\mathrm{DPSC}_{2}$ was isolated from the third molar of a 22 year old male. The isolation procedure and usage of DPSC was approved by the Ethical Committee of the Faculty hospital Hradec Králové and both donors signed an informed consent. Both lines were isolated according to the procedures described previously (23). Briefly: Third molars were extracted under sterile conditions and transported to a tissue culture laboratory in $4{ }^{\circ} \mathrm{C}$ cold Hank's balanced salt solution (Gibco, UK). Roots of the third molars were broken using Luer's forceps, vital pulp was removed using extirpation needle or tweezers through the root canal. Then the pulp tissue was exposed to enzymatic dissociation collagenase (Sevapharma, Czech Republic) and dispase (Gibco, UK) for $70 \mathrm{mi}-$ nutes. Followed by a centrifugation $(600 \mathrm{~g}, 5 \mathrm{~min}$.) we have obtained a cell pellet.

\section{Cultivation}

DPSC were cultivated on untreated plastic until they reached $70 \%$ confluence. Then were detached from the cultivation flasks using trypsin-EDTA (Gibco, Scotland) and seeded into a new cultivation flasks in the density of $4500 / \mathrm{cm}^{2}$. Both lines of DPSC were cultivated for 15 passages to bypass the Hayflick's limit in $5 \% \mathrm{CO}_{2}$ atmosphere under $37^{\circ} \mathrm{C}$ in the standard cultivation medium composed of alfa-MEM (Gibco, UK), 2\% FCS (PAA, USA), 10ng/ml EGF (PeproTech, USA), 10ng/ml PDGF (PeproTech, USA), $0.2 \mathrm{mM} \mathrm{L} \mathrm{-} \mathrm{ascorbic} \mathrm{acid} \mathrm{(Sigma,}$ USA), 2\% glutamine (Gibco, UK), $100 \mathrm{U} / \mathrm{ml}$ penicillin, $100 \mu \mathrm{g} / \mathrm{ml}$ streptomycin (Gibco, USA), $50 \mathrm{nM}$ dexamethasone (Sigma, USA) and $10 \mu \mathrm{l} / \mathrm{ml}$ ITS (catalog number I3146, Sigma, USA). To prove their ability to differentiate we chose an osteogenic differentiation media composed of $\alpha$-MEM (Invitrogen, USA) s 10\% FCS (PAA, USA), $0.2 \mathrm{mM}$ L-ascorbic acid (Sigma, USA), $10 \mathrm{mM} \beta$-glycerolphosphate (Sigma, USA), and $0.1 \mu \mathrm{M}$ dexamethasone (Invitrogen, USA). For osteogenic differentiation we used DPSC $_{1}$ and DPSC $_{2}$ cultivated in media with $10 \%$ FCS and $2 \%$ FCS with ITS obtained from 6 th passage. Cells were incubated in a monolayer, osteogenic medium for four weeks. Samples were stained according to Ladewigs protocol.

\section{Tested media composition}

DPSC were cryopreserved in the third passage. After it was approved that both lines can bypass Hayflick's limit and undergo differentiation, cryopreserved cells were thawed and seeded into four different media. In these media the cells were cultivated from 3 rd to 9 th passage. Media A composed of alfa-MEM, 2\% FCS, $10 \mathrm{ng} / \mathrm{ml} \mathrm{EGF,} 10 \mathrm{ng} / \mathrm{ml}$ PDGF, $0.2 \mathrm{mM}$ L-ascorbic acid, 2\% glutamine, $100 \mathrm{U} / \mathrm{ml}$ penicilin/ $100 \mu \mathrm{g} / \mathrm{ml}$ streptomycin (Gibco, UK), $20 \mu \mathrm{g} / \mathrm{ml}$ gentamycin, $50 \mathrm{nM}$ dexamethasone (Sigma, USA) and $10 \mu \mathrm{l} / \mathrm{ml}$ ITS (catalog number I3146, Sigma, USA) is our standard cultivation media and DPSC cultivated in this media were used as control group.

Tested media were composed of B) alfa-MEM, 2\% FCS, $10 \mathrm{ng} / \mathrm{ml} \mathrm{EGF,} 10 \mathrm{ng} / \mathrm{ml}$ PDGF, $1 \mathrm{ng} / \mathrm{ml} \mathrm{FGF-2}$ (PeproTech, USA), $0.2 \mathrm{mM}$ L-ascorbic acid, 2\% glutamine, $100 \mathrm{U} / \mathrm{ml}$ penicilin/ $100 \mu \mathrm{g} / \mathrm{ml}$ streptomycin (Gibco, $\mathrm{UK}$ ), $20 \mu \mathrm{g} / \mathrm{ml}$ gentamycin, $50 \mathrm{nM}$ dexamethasone (Sigma, USA), C) alfa-MEM, 10\% FCS, $0.2 \mathrm{mM} \mathrm{L-ascorbic} \mathrm{acid,}$ $2 \%$ glutamine, $100 \mathrm{U} / \mathrm{ml}$ penicilin/ $100 \mu \mathrm{g} / \mathrm{ml}$ streptomycin (Gibco, UK), $20 \mu \mathrm{g} / \mathrm{ml}$ gentamycin and D) alfa-MEM, 10\% FCS, $0.2 \mathrm{mM}$ L-ascorbic acid, $2 \%$ glutamine, $100 \mathrm{U} / \mathrm{ml}$ penicilin/ $100 \mu \mathrm{g} / \mathrm{ml}$ streptomycin (Gibco, UK), $20 \mu \mathrm{g} / \mathrm{ml}$ gentamycin, and $1 \mathrm{ng} / \mathrm{ml} \mathrm{FGF-2.}$

\section{Characterization}

During whole cultivation, number of population doublings (PD) and doubling time (DT) were measured using Vi-Cell analyzer and Z2-Counter (both from Beckman Coulter, USA). Karyotyping cells (subcultured at a 1:3 dilution, both early passages and after bypassing Hayflick's limit) were subjected to a 4-hour Demecolcemid (Sigma, USA) incubation after 24 hours cultivation followed by trypsin-EDTA detachment and lysis with hypotonic $\mathrm{KCl}$ and fixation in acid/alcohol. Metaphases were analyzed after GTG banding using software Ikaros v5.0 (MetaSystems, USA). The karyotype was examined in the 3rd, 5th and 7 th passages. For phenotypic analysis cells (DPSCs passage No. 5) were detached and stained sequentially with immunofluorescent primary antibodies. The percentage of positive cells was determined as the percentage of cells with higher fluorescence intensity than the upper $0.5 \%$ isotype immunoglobulin control. Classification criteria: $<10 \%$ no expression, $11-40 \%$ low expression, $41-70 \%$ moderate expression and $>71 \%$ high expression. DPSCs cultivated in media A, B, C and D were analyzed for CD29 (BD Biosciences Pharmingen, Belgium), CD31 (Invitrogen, California, USA), CD34 (Dako, Denmark), CD44 (BD Biosciences Pharmingen, Belgium), CD45 (Dako, Denmark), CD71 (Dako, Denmark), CD73 (BD Biosciences Pharm., 
Belgium), CD90 (BD Biosciences Pharmingen, Belgium), CD105 (nvitrogen, California, USA), CD106 (Biolegend, California, USA), CD117 (eBioscience, USA), CD133 (eBioscience, USA), CD166 (Immunotech, France), and CD184 (Invitrogen, California, USA).

\section{Statistics}

The descriptive statistics of the results were calculated and the charts were made in either Microsoft Office Excel 2010 (Microsoft, Redmond, WA). In this study, all the values were expressed as arithmetic means with SD.

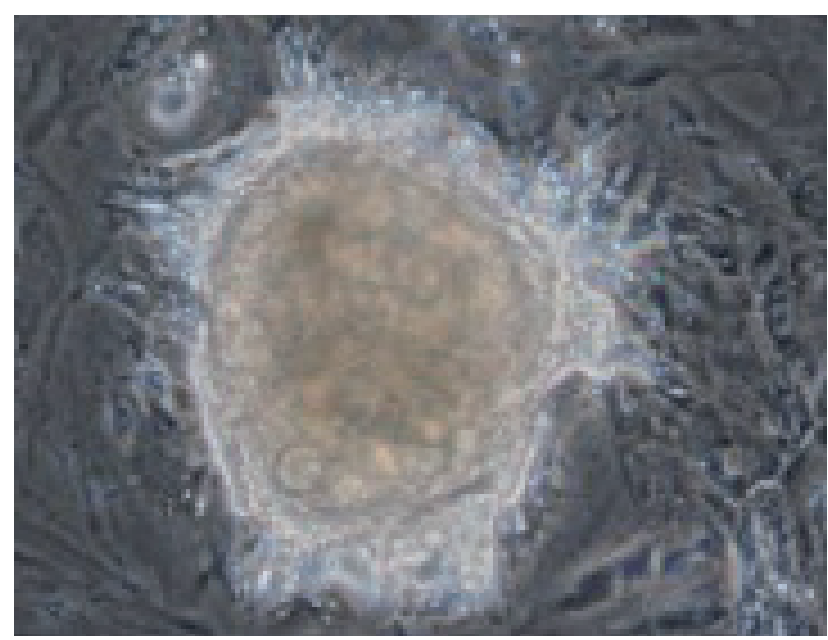

Fig. 1: Three-dimensional particle of extracellular matrix cre-

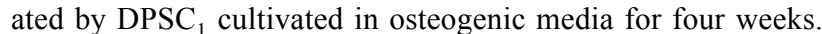
Phase-contrast microscope, original magnification $200 \times$.

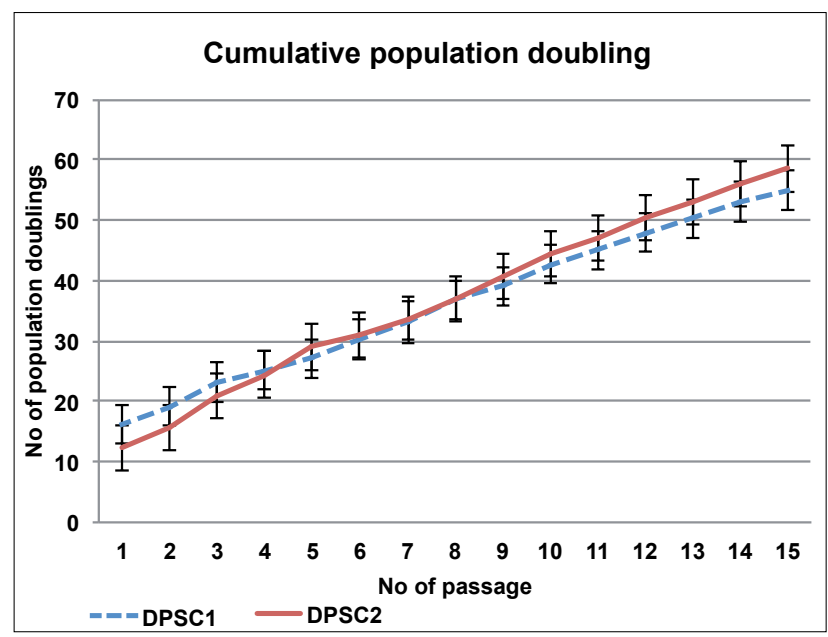

Graph 1: Both lines of tested DPSC were able to reach 50 population doublings in stadard cultivation medium. Number of total PD for $\mathrm{DPSC}_{1}$ was 54.94 (on the average $3.66+/-0.62$ per passage), for $\mathrm{DPSC}_{2}$ was 61.25 (on the average $3.83+/-0.83$ per passage).

\section{Results}

We successfully isolated two lines of DPSC. Both lines DPSC $_{1}$ and DPSC $_{2}$ were cultivated and bypassed Hayflick's limit in the standard cultivation medium. Medium A is our standard cultivation media and DPSC cultivated in this media were used as control group. Number of total PD for $\mathrm{DPSC}_{1}$ was 54.94 (on the average $3.66+/-0.62$ per passage), for $\mathrm{DPSC}_{2}$ was 61.25 (on the average $3.83+/-0.83$ per passage) (Graph 1). Average DT was 27.59+/-6.24 for

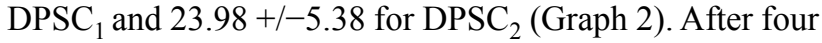
weeks of osteogenic differentiation both lines of DPSC cultivate media with $2 \%$ FCS and ITS (medium A) and in

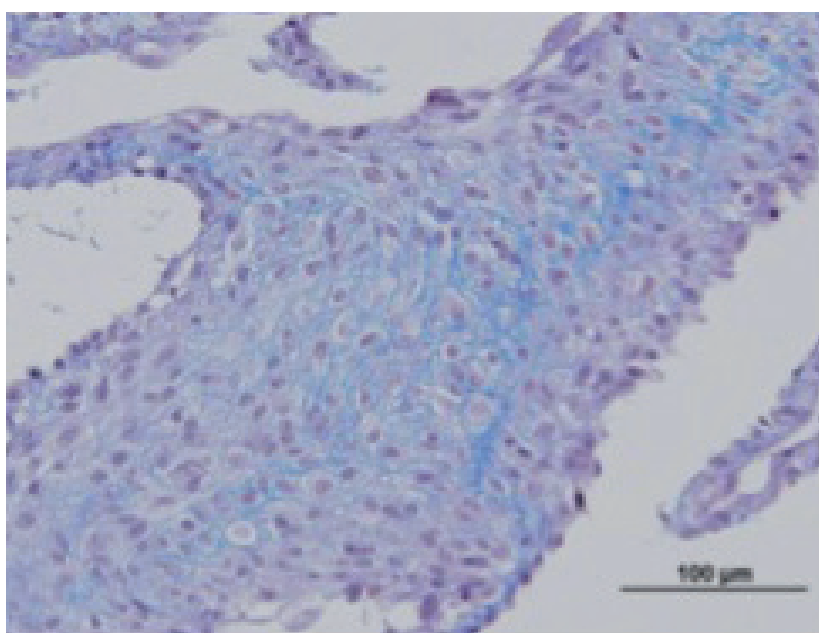

Fig. 2: Cell pellet of DPSC $_{1}$ cultivated in osteogenic media for four weeks stained according to Ladewig's protocol. Blue color showed osteoid.

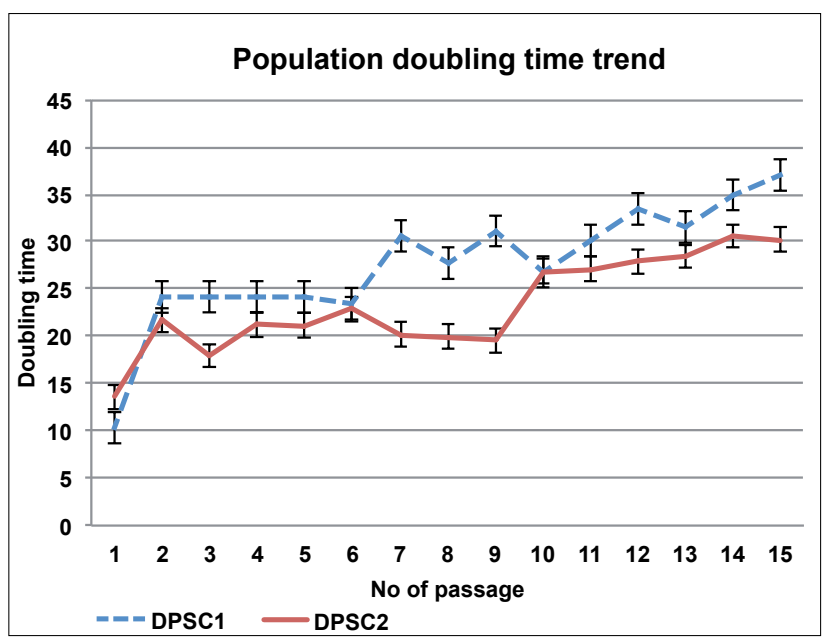

Graph 2: Population doubling time trend show slowly increasing DT during the long term cultivation. Average DT was 27.59 $+/-6.24$ for $\mathrm{DPSC}_{1}$ and $23.98+/-5.38$ for $\mathrm{DPSC}_{2}$. 
media with 10\% FCS (medium C) produced extracellular matrix, which formed 3-dimensional aggregates (Fig. 1). After Ludewig's staining we proved the presence of an osteoid matrix (Fig. 2).

For our study the DPSC from 3rd passage were used. For the first 3 passages those cells were cultivated in medium A. From the 4th till 9th passage the DPSC were cultivated in four tested media. During the cultivation we observed the DPSC from both lines showed different proliferation ability in dependence on the cultivation media. The highest number of cumulative PD and lowest average DT showed

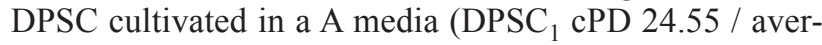
age DT $24.45+/-2.66$ hours, DPSC $_{2}$ cPD 26.36 / average DT $23.38+/-4.38$ hours). In average during one passage the DPSC cultivated in a media A were able to made 3.51 $+/-0.33$ PD for $\mathrm{DPSC}_{1}$ and $3.77+/-0.68$ for $\mathrm{DPSC}_{2}$. C and $\mathrm{D}$ media showed almost the same results $\left(\mathrm{C}-\mathrm{DPSC}_{1} \mathrm{cPD}\right.$

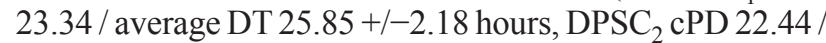
average DT $27.28+/-5.19$ hours, D-DPSC 1 cPD $23.10 /$ average DT $26.05+/-2.13$ hours, DPSC $_{2}$ cPD $22.59 /$ average DT $26.90+/-4.27$ hours). In average during one passage the DPSC cultivated in a media $\mathrm{C} / \mathrm{D}$ were able to made $3.33+/-0.53 / 3.30+/-0.46 \mathrm{PD}$ for $\mathrm{DPSC}_{1}$ and 3.21 $+/-0.47 / 3.23+/-0.44$ for $\mathrm{DPSC}_{2}$. The smallest proliferation ability was found in media $\mathrm{B}\left(\mathrm{DPSC}_{1}\right.$ cPD 12.97 / average DT $49.91+/-17.89$ hours, DPSC $_{2}$ cPD 14.33 / average DT $44.43+/-13.41$ hours). In average during one passage the DPSC cultivated in a media $\mathrm{B}$ were able to made $1.85+/-0.45 \mathrm{PD}$ for $\mathrm{DPSC}_{1}$ and $2.05+/-0.43 \mathrm{v}$ for $\mathrm{DPSC}_{2}$ (Graph 3, 4) (Tab. 1, 2).

Tab. 1: The highest number of PD was observed in the A media, $\mathrm{C}$ and $\mathrm{D}$ media showed almost the same results and the smallest proliferation ability was found in media B.

\begin{tabular}{|l|l|l|l|}
\hline \multicolumn{4}{|c}{$\mathrm{PD}-\mathrm{DPSC}_{1} / \mathrm{DPSC}_{2}$} \\
\hline & Cumulative & PD/passage & $\begin{array}{c}\text { Standard } \\
\text { deviation }\end{array}$ \\
\hline Medium A & $24.55 / 26.36$ & $3.51 / 3.77$ & $0.33 / 0.68$ \\
\hline Medium B & $12.97 / 14.33$ & $1.85 / 2.05$ & $0.45 / 0.43$ \\
\hline Medium C & $23.34 / 22.44$ & $3.33 / 3.21$ & $0.53 / 0.47$ \\
\hline Medium D & $23.10 / 25.59$ & $3.30 / 3.23$ & $0.46 / 0.44$ \\
\hline
\end{tabular}

Tab. 2: Lowest average DT showed DPSC cultivated in the A media, $\mathrm{C}$ and $\mathrm{D}$ media showed almost the same results and the highest DT was found in media B.

\begin{tabular}{|l|l|l|}
\hline \multicolumn{3}{|c|}{ DT - DPSC $_{1} / \mathrm{DPSC}_{2}$} \\
\hline & Average & Standarddeviation \\
\hline Medium A & $24.45 / 23.38$ & $2.66 / 4.38$ \\
\hline Medium B & $49.91 / 44.43$ & $17.88 / 13.41$ \\
\hline Medium C & $25.85 / 27.28$ & $2.18 / 5.18$ \\
\hline Medium D & $26.05 / 26.90$ & $2.13 / 4.27$ \\
\hline
\end{tabular}

Analysis of karyotype in DPSC cultivated in media with $10 \%$ of FCS showed more chromosomal aberration than in DPSC cultivated in media with $2 \%$ of FCS. In each analysis we tried to reach 25 checked mitoses. DPSC 1 $\mathrm{DPSC}_{2}$ cultivated in medium A showed a stable karyotype until the 9 th passage. Both lines in passage 9 showed chromosomal aberrations (DPSC $2-1$ break of chromosome 17 in 25 checked mitoses, DPSC $1-2$ breaks of chromosomes 1 and 8 in 7 checked mitoses). Because of low proliferation of both lines in media B we cannot satisfactorily evaluate chromosomal stability during long term cultivation. We were able to find one case of deletion (chromosome 5) in 25 mitoses in $\mathrm{DPSC}_{2}$ in passage 5 . DPSC 1 cultivated in media $\mathrm{C}+\mathrm{D}$ showed chromosomal abnormality in passage 5 ( 1 break of chromosome 10 for medium $\mathrm{C}$ and 1 break of chromosome 9 for medium D in 25 checked mitoses) and in passage 9 (four tetraploids in 7 and 5 mitoses in both media). DPSC ${ }_{2}$ cultivated in media D showed first chromosomal instability in a passage 5 where we found 1 break of chromosome 22 in 25 mitoses. For medium $\mathrm{C}$ we found one break of chromosome 17 from 25 mitoses in 7 th passage. In 9th passage we found two breaks of chromosomes 3 and 8 ,

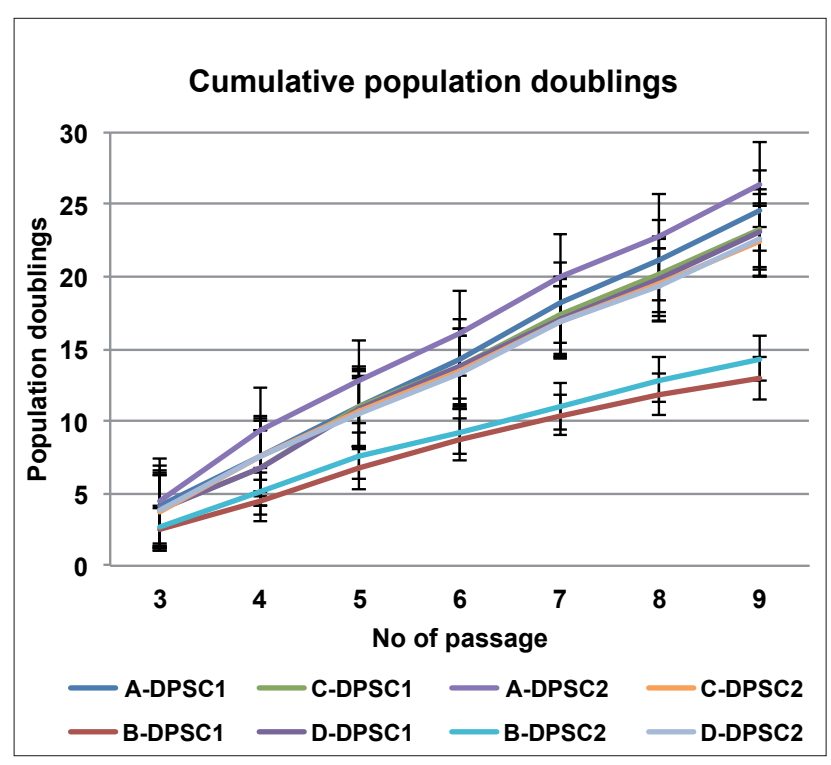

Graph 3: During the cultivation in tested media we were able to reach from $12-26$ PD. DPSC cultivated in a media B showed the slowest proliferation rate, the highest proliferation rate was observed in DPSC cutivated in a media A. DPSC 1 cPD 24.55, $\mathrm{DPSC}_{2} \mathrm{cPD} 26.36$, in average during one passage the DPSC cultivated in a media A were able to made $3.51+/-0.33$ PD for DPSC and $3.77+/-0.68$ for $\mathrm{DPSC}_{2}$. The cPD for DPSC cultivated in media C and D was cPD C-DPSC $1=23.34$, DPSC $_{2}=22.44$, D-DP$\mathrm{SC}_{1}=23.10, \mathrm{DPSC}_{2}=22.59$. In average during one passage the DPSC cultivated in a media $\mathrm{C} / \mathrm{D}$ were able to made $3.33+/-0.53 /$ $3.30+/-0.46$ PD for $\mathrm{DPSC}_{1}$ and $3.21+/-0.47 / 3.23+/-0.44$ for DPSC $_{2}$. The cPD for DPSC cultivated in media B was DPSC cPD 12.97, $\mathrm{DPSC}_{2} \mathrm{cPD} 14.33$. In average during one passage the DPSC cultivated in a media $\mathrm{B}$ were able to made $1.85+/-0.45 \mathrm{PD}$ for $\mathrm{DPSC}_{1}$ and $2.05+/-0.43$ for $\mathrm{DPSC}_{2}$. 
moreover we observed remodeling of chromosomes 1 and 14 in 15 mitoses in medium $\mathrm{C}$ and two tetraploids from 14 mitoses in medium D (Tab. 3).

For $\mathrm{DPSC}_{1}$ line phenotypic analysis showed high positivity for CD29 (medium A - 99.4\%, medium B - 99.5\%, medium C - 99.7\%, medium D - 98.6\%), CD44 (medium A - 99.7\%, medium B - 98.8\%, medium C - 99.9\%, medium D - 99.0\%), CD73 (medium A - 98.9\%, medium B 99.8\%, medium C - 99.4\%, medium D - 99.6\%), CD166 (medium A - 94.6\%, medium B - 99.1\%, medium C $99.3 \%$, medium D - 99.7\%) in all tested media. Moreover we found high positivity for CD90 in medium A (87.7\%), medium C (96.5\%) and medium D (97.9\%). Moderate positivity was found only in media A for CD106 (47.0\%). Low positivity in medium A was found for CD45 (15.8\%), CD71 (29.2\%), CD117 (16.5\%) and CD133 (35.4\%), in medium B was found for CD90 (36.7\%) and CD117 (14.4\%), in medium $\mathrm{C}$ was found for CD105 (13.5\%) and for medium $\mathrm{D}$ there were not found any $\mathrm{CD}$ with low positivity. No expressions were found for CD31 (medium A $-6.5 \%$, medium $\mathrm{B}-0.0 \%$, medium $\mathrm{C}-0.1 \%$, medium $\mathrm{D}-0.2 \%$, CD34 (medium $\mathrm{A}-0.2 \%$, medium $\mathrm{B}-0.1 \%$, medium $\mathrm{C}$ $-0.2 \%$, medium D - 0.3\%), CD45 (medium B - 1.1\%, medium $\mathrm{C}-0.1 \%$, medium $\mathrm{D}-1.0 \%$ ), CD71 (medium $\mathrm{B}-0.6 \%$, medium $\mathrm{C}-0.8 \%$, medium $\mathrm{D}-1.1 \%)$, CD105 (medium B - 2.5\%, medium D - 5.7\%), CD106 (medium $\mathrm{A}-0.1 \%$, medium $\mathrm{B}-0.5 \%$, medium $\mathrm{C}-0.2 \%$, medium

Tab. 3: Results of the karyotype analysis with specified amount of tested mitosis, amount and description of aberration in all tested media for both cell lines.

\begin{tabular}{|c|c|c|c|c|}
\hline \multicolumn{5}{|c|}{$\mathrm{DPSC}_{1}$} \\
\hline \multirow{2}{*}{ Passage } & \multirow{2}{*}{ Medium } & \multirow{2}{*}{$\begin{array}{c}\text { No of } \\
\text { mitosis }\end{array}$} & \multicolumn{2}{|r|}{ Aberration } \\
\hline & & & Number & Description \\
\hline \multirow{4}{*}{3} & A & 25 & 0 & \\
\hline & B & 25 & 0 & \\
\hline & $\mathrm{C}$ & 25 & 0 & \\
\hline & $\mathrm{D}$ & 25 & 0 & \\
\hline \multirow{4}{*}{5} & A & 25 & 0 & \\
\hline & B & 4 & 0 & \\
\hline & $\mathrm{C}$ & 25 & 1 & break chr. 10 \\
\hline & $\mathrm{D}$ & 25 & 1 & break chr. 9 \\
\hline \multirow{4}{*}{7} & $\mathrm{~A}$ & 25 & 0 & \\
\hline & $\mathrm{B}$ & 0 & 0 & \\
\hline & $\mathrm{C}$ & 25 & 1 & break chr. 10 \\
\hline & $\mathrm{D}$ & 25 & 0 & \\
\hline \multirow{4}{*}{9} & $\mathrm{~A}$ & 7 & 2 & break chr. 1,8 \\
\hline & $\mathrm{B}$ & 4 & 0 & \\
\hline & $\mathrm{C}$ & 7 & 4 & tetraploid \\
\hline & $\mathrm{D}$ & 5 & 4 & tetraploid \\
\hline
\end{tabular}

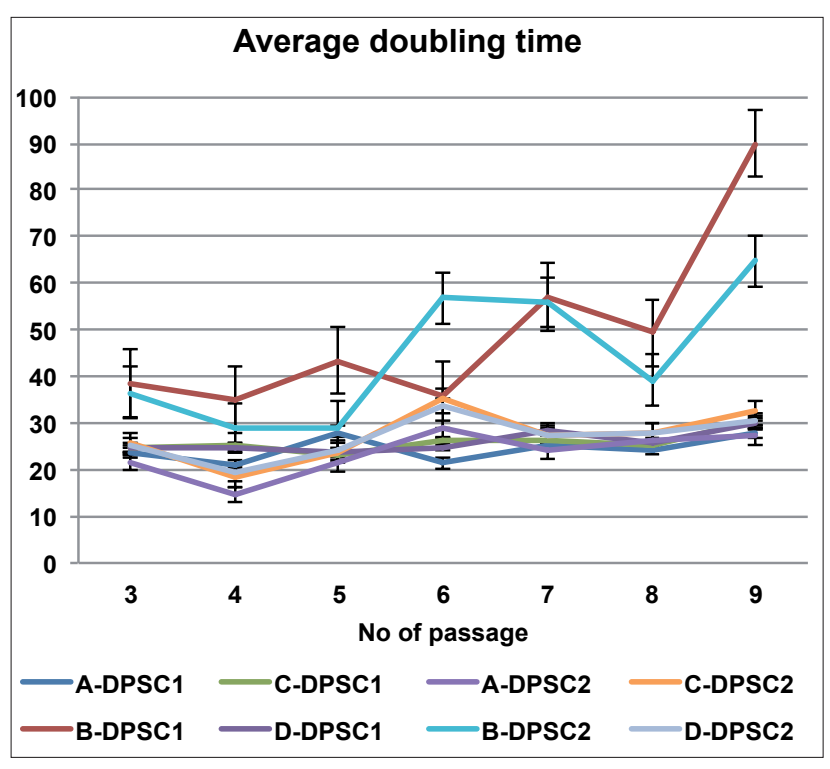

Graph 4: Population doubling time trend indicates increasing DT during the long term cultivation in all four tested media. In media A average DT for DPSC ${ }_{1}$ was $24.45+/-2.66$ hours, for $\mathrm{DPSC}_{2}$ was $23.38+/-4.38$ hours. In media C average DT for DPSC Das $_{1}$ $25.85+/-2.18$ hours, for DPSC $_{2}$ was DT $27.28+/-5.19$ hours. In media D average DT for DPSC $_{1}$ was $26.05+/-2.13$ hours, DPSC $_{2}$ was $26.90+/-4.27$ hours. In media $\mathrm{B}$ average $\mathrm{DT}$ for $\mathrm{DPSC}_{1}$ was $49.91+/-17.89$ hours, for DPSC $_{2}$ was $44.43+/-13.41$ hours.

\begin{tabular}{|c|c|c|c|c|}
\hline \multicolumn{5}{|c|}{$\mathrm{DPSC}_{2}$} \\
\hline \multirow{2}{*}{ Passage } & \multirow{2}{*}{ Medium } & \multirow{2}{*}{$\begin{array}{l}\text { No of } \\
\text { mitosis }\end{array}$} & \multicolumn{2}{|c|}{ Aberration } \\
\hline & & & Number & Description \\
\hline \multirow{4}{*}{3} & A & 25 & 0 & \\
\hline & B & 25 & 0 & \\
\hline & $\mathrm{C}$ & 25 & 0 & \\
\hline & $\mathrm{D}$ & 25 & 0 & \\
\hline \multirow{4}{*}{5} & A & 25 & 0 & \\
\hline & B & 25 & 1 & deletion chr. 5 \\
\hline & $\mathrm{C}$ & 13 & 0 & \\
\hline & $\mathrm{D}$ & 25 & 1 & break chr. 22 \\
\hline \multirow{4}{*}{7} & A & 25 & 0 & \\
\hline & B & 4 & 0 & \\
\hline & $\mathrm{C}$ & 25 & 1 & break chr. 17 \\
\hline & $\mathrm{D}$ & 25 & 0 & \\
\hline \multirow{4}{*}{9} & A & 25 & 1 & break chr. 7 \\
\hline & B & 0 & 0 & \\
\hline & $\mathrm{C}$ & 15 & 3 & $\begin{array}{l}\text { break chr. } 3,8, \\
\text { chr. remodeling } \\
1 \text { and } 14\end{array}$ \\
\hline & D & 14 & 2 & tetraploid \\
\hline
\end{tabular}


$\mathrm{D}-0.0 \%$ ), CD117 (medium C - 9.1\%, medium D - 5.6\%), CD133 (medium B - 1.6\%, medium C $-2.1 \%$, medium D $-2.0 \%$ ) and CD184 (medium A $-1.7 \%$, medium B $-2.0 \%$, medium $\mathrm{C}-0.8 \%$, medium D - 0.4\%) (Graph 5) (Tab. 4).

For $\mathrm{DPSC}_{2}$ line phenotypic analysis showed high positivity for CD29 (medium A - 99.1\%, medium B - 99.6\%, medium $\mathrm{C}-99.7 \%$, medium D - 99.3\%), CD44 (medium A-99.3\%, medium B - 99.7\%, medium C-99.5\%, medium D - 99.6\%), CD73 (medium A - 98.7\%, medium B - 99.6\%, medium C - 99.5\%, medium D - 99.1\%), CD166 (medium A - 98.3\%, medium B - 99.0\%, medium C - 99.1\%, medium D-99.1\%) in all tested media. Moreover we found high positivity for CD90 in medium D (98.0\%). Moderate positivity was found in medium A for CD71 (42.1\%), CD90 (70.5\%), CD105 (70.3\%), in medium B for CD90 (57.0\%) and in medium $\mathrm{C}$ for CD105 (41.3\%). Low positivity was found in medium A for CD45 (12.4\%) and CD133 (21.9\%). Low positivity was found in medium B for CD117 (15.0\%) and in medium D for CD105 (25.9\%) and CD117 (11.9\%). No $\mathrm{CD}$ with low positivity was found in medium $\mathrm{C}$. No expressions were found for CD31 (medium $\mathrm{A}-7.6 \%$, medium $\mathrm{B}-0.2 \%$, medium $\mathrm{C}-0.2 \%$, medium $\mathrm{D}-0.1 \%$ ), CD34 (medium $\mathrm{A}-0.3 \%$, medium $\mathrm{B}-0.0 \%$, medium $\mathrm{C}-0.1 \%$, medium D - 0.1\%), CD45 (medium B - 1.2\%, medium $\mathrm{C}-3.8 \%$, medium D $-2.0 \%$ ), CD71 (medium B - 0.9\%, medium $\mathrm{C}-0.9 \%$, medium D - 4.9\%), CD105 (medium $\mathrm{B}-9.5 \%$ ), CD106 (medium A - 0.0\%, medium B - 0.2\%, medium $\mathrm{C}-0.1 \%$, medium D - 0.9\%), CD117 (medium $\mathrm{A}-1.4 \%$, medium $\mathrm{C}-9.9 \%$ ), CD133 (medium B - 1.6\%, medium $\mathrm{C}-4.0 \%$, medium $\mathrm{D}-1.1 \%$ ) and CD184 (medium $\mathrm{A}-2.0 \%$, medium $\mathrm{B}-0.3 \%$, medium $\mathrm{C}-0.7 \%$, medium $\mathrm{D}-1.0 \%$ ). We were not able to measure the expression of DPSC2 for CD90 in medium C because of technical failure during phenotypic analysis (Graph 6) (Tab. 4).

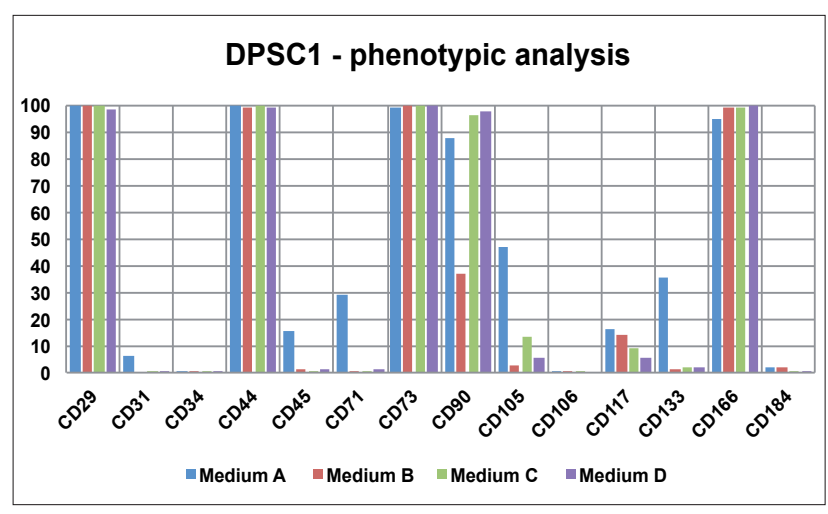

Graph 5: Phenotypic analysis of $\mathrm{DPSC}_{1}$ cultivated in all tested media in passage No. 9 .

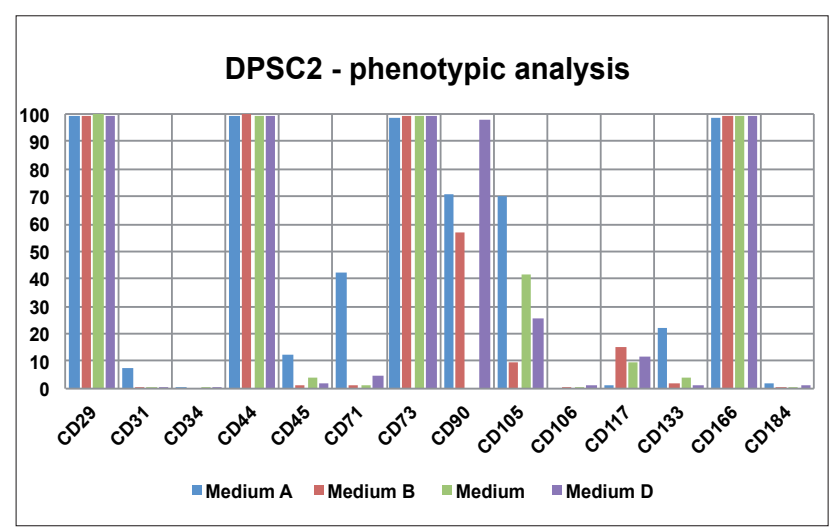

Graph 6: Phenotypic analysis of $\mathrm{DPSC}_{2}$ cultivated in all tested media in passage No. 9.

Tab. 4: Phenotypic analysis of DPSC ${ }_{1}$ and DPSC 2 cultivated in tested media in passage No. 9. The value is a percentage expression of the CD.

\begin{tabular}{|l|c|c|c|c|c|c|c|c|}
\hline & \multicolumn{4}{|c}{ DPSC $_{1}$} & \multicolumn{4}{c|}{ DPSC $_{2}$} \\
\hline & Medium A & Medium B & Medium C & Medium D & Medium A & Medium B & Medium C & Medium D \\
\hline CD29 & 99.4 & 99.5 & 99.7 & 98.6 & 99.1 & 99.6 & 99.7 & 99.3 \\
\hline CD31 & 6.5 & 0.0 & 0.1 & 0.2 & 7.6 & 0.2 & 0.2 & 0.1 \\
\hline CD34 & 0.2 & 0.1 & 0.2 & 0.3 & 0.3 & 0.0 & 0.1 & 0.1 \\
\hline CD44 & 99.7 & 98.8 & 99.9 & 99.0 & 99.3 & 99.7 & 99.5 & 99.6 \\
\hline CD45 & 15.8 & 1.1 & 0.1 & 1.0 & 12.4 & 1.2 & 3.8 & 2.0 \\
\hline CD71 & 29.2 & 0.6 & 0.8 & 1.1 & 42.1 & 0.9 & 0.9 & 4.9 \\
\hline CD73 & 98.9 & 99.8 & 99.4 & 99.6 & 98.7 & 99.6 & 99.5 & 99.1 \\
\hline CD90 & 87.7 & 36.7 & 96.5 & 97.9 & 70.5 & 57.0 & NA & 98.0 \\
\hline CD105 & 47.0 & 2.5 & 13.5 & 5.7 & 70.3 & 9.5 & 41.3 & 25.9 \\
\hline CD106 & 0.1 & 0.5 & 0.2 & 0.0 & 0.0 & 0.2 & 0.1 & 0.9 \\
\hline CD117 & 16.5 & 14.4 & 9.1 & 5.6 & 1.4 & 15.0 & 9.9 & 11.9 \\
\hline CD133 & 35.4 & 1.6 & 2.1 & 2.0 & 21.9 & 1.6 & 4.0 & 1.1 \\
\hline CD166 & 94.6 & 99.1 & 99.3 & 99.7 & 98.3 & 99.0 & 99.1 & 99.1 \\
\hline CD184 & 1.7 & 2.0 & 0.8 & 0.4 & 2.0 & 0.3 & 0.7 & 1.0 \\
\hline
\end{tabular}




\section{Discussion}

Fetal calf serum is a widely used media supplement which can highly affect cultivated cells and the results of the experiments (19). FCS is so widely used because it contains high amount of growth stimulatory factors and it is cheap. On the other hand, because it is not manufactured but extracted from calves and their natural products, its composition varied not only between producers, but even between each batches from the same producer. The scientist cannot be sure how much their results will be influenced and repeatable (24).

In our studies we are focused on decreasing amount, or better discarding the FCS from cultivation media since 2005. In the previous studies we were able to reduce the FCS to $2 \%$, but still we were not able to discard it totally. In this study we tried to compare the effect of higher concentration of FCS to the DPSC. It is well known, that high amount (about $40 \%$ ) is even toxic for the cultivated cells. So surely there has to be some negative side effect of FCS on the cells. In this study we tried to find some of these side effects by comparing the DPSC cultivated in 4 different media containing $2 \%$ or $10 \%$ of FCS and substituted with growth factors. We proved that the FCS can have critical side effect at least on chromosomal stability of the cultivated cells and affect the phenotype of cultivated cells.

We were analyzing proliferation activity, karyotype and phenotype of 2 lines of DPSC cultured in media with different amount of FCS and substituted with different growth factors. To acquire comparative results we cultivated DPSC from two donors and after reaching a sufficient amount of DPSC we split each line into 4 cultivation flasks with different media. Unlike other investigators $(25,26)$ we cultured both lines over 40 population doublings in the tested media A, C, D (about 20 PD from initial 3 passages + at least 22 passages in tested media). We proved, that using 10\% FCS medium can highly affect proliferation activity of DPSC (results from samples C + D) in compare to $2 \%$ FCS medium (samples B), but when adding ITS in to $2 \%$ FCS medium (samples A) proliferation activity will be even faster than in media containing $10 \%$ FCS media. Some authors reported that usage of FGF-2 can lead to higher proliferation ability of MSC and does not affect their differentiation ability $(27,28)$. In contrast with another study by Sotiropoulou (29) in which FGF-2 was used in different concentrations and mitogenic activity was proven, we found that proliferation activity did not improve significantly when adding FGF-2 to cultivated in media. The main difference was the positivity for CD105, where DPSC cultivated in media without FGF-2 had higher positivity. The difference between our findings and the findings of the other mentioned author can be explained by different stem cells population. All cited authors used bone marrow stem cells, and we did not find any article describing the effect of FGF-2 on DPSC.

Analysis of karyotype showed that DPSC cultivated in media containing $10 \%$ of FCS had significantly more chromosomal aberrations than those cultivated in medium containing only $2 \%$ FCS and ITS. Chromosamal aberration during in vitro expansion did not represent high risk for the researchers. Those cells probably undergo apoptosis and will not effect the results, but the it surely represents unacceptable risks for the patients when used in human medicine. After 6 passages in cultivation media containing $10 \%$ of FCS the chromosomal aberration occurred in 8/12 of checked mitosis in DPSC $_{1}$ line and in $5 / 29$ of checked mitosis in $\mathrm{DPSC}_{2}$ line, compare to 2 aberration of 11 checked mitosis in $\mathrm{DPSC}_{1}$ line and in 1 aberration of 25 checked mitosis in $\mathrm{DPSC}_{2}$ line cultivated in media containing $2 \%$ of FCS. The most frequently observed aberrations in DPSC lines cultivated in 10\% FCS media were tetraploid. In compare to structural aberrations observed in DPSC lines cultivated in $2 \%$ FCS, numerical aberrations are more severe. We did not find any article that described this side effect, but in these days more authors worldwide warns again using FCS as the supplement for cultivation media (30) and offers possible ways of how the FCS can be replaced by other substituent (e.g. human blood serum) (31). Even that these aberrations seems not to be clonal because they did not occur repeatedly we are supposed to be wary when some stem cells cultivated in medium containing FCS are used in human medicine.

Because of low proliferation activity we were not able to compare the results with medium containing only $2 \%$ FCS without ITS. This results evokes a new question; does the FCS in higher concentration cause more chromosomal aberrations, or does the usage of FCS result in chromosomal aberrations while the ITS supplement protects the cells? We have to continue with new experiments to answer this question.

Our phenotypic analysis supports our previous findings (32). DPSC showed high or moderate positivity (in the case ITS was added into cultivation media) for mesenchymal stem cell markers (CD29, CD44, CD90 and for CD166 which is also known as ALCAM [Activated leukocyte cell adhesion molecule]) which is a cell surface sensor for cell density and regulates cell migration. Adding ITS supplement into the cultivation media leads to higher expression of CD45, CD71, CD105 and CD133. The higher expression of CD45 (recognize leukocyte common antigen, monocytes and T-cell subset), CD105 (Endoglin, part of the TGF-beta1 receptor komplex) which plays a role in the binding of TGF-beta1, TGF-beta3, activin-A, BMP-2 and BMP-7 and CD133 (hematopoietic stem cells, endothelial progenitor cells, glioblastoma, neuronal and glial stem cells) supports the idea that ITS supplement keeps the DPSC less differentiated and prepared for wider differentiation into mature cells lines. Higher expression of CD71 (receptor for transferrin) in a medium with ITS supplement can be explained by the presence of transferrin in cultivation media. This receptor helps the cells import the transferrin-iron complex into the cells through endocytosis. We found that decreasing concentrations of FCS leads to decreasing expression of CD90 (in medium B falls even into low positivity for $\mathrm{DPSC}_{1}$ and 
into moderate positivity on media $\mathrm{A}, \mathrm{B}$ for $\mathrm{DPSC}_{2}$ ). We are not able to explain this side effect.

\section{Conclusion}

Even though some animal component free media are known and already tested, we are far from using FCS free media during in vitro MSC experiments. Even when some clinical trials reported usage of FCS in patient treatment without any side effects, there is no doubt that usage of FCS should be avoided in future human medicine. In our study we proved that fetal calf serum in cultivation media can affect the phenotype profile of cultivated dental pulp stem cells, but moreover it cause chromosomal aberration. These side effects of cultivation can lead into a false result or even more when used in human medicine. The risk of transmission of zoonosis or inducing immunization of the recipients is well known, but the risk of malignant transformation is relatively new problem. If the clinicians will count on the preclinical studies results it can lead not just to the failure of the clinical treatment but also to the threat of patient health. Research with MSC should continue but scientists should also be aware about the results acquired from cells cultivated in media containing high concentration of FCS because it surely affects the basic biological properties of DPSC.

\section{Acknowledgements}

This work was supported by the programme PRVOUK P37/06. Authors would like thank to MDDr. Antranig Haig Manugian for the helping with manuscript preparation.

\section{References}

1. Minguel JJ, Erices A, Conget P. Mesenchymal stem cells. Exp Biol Med, 2001; 226: 507-20.

2. Reyes M, Lund T, Lenvik T, et al. Purification and ex vivo expansion of postnata human marrow mesodermal progenitor cells. Blood, 2001; 9(98): 2615-25.

3. Werntz JR, Lane JM, Burstein AH, et al. Qualitative and quantitative analysis of orthotopic bone regeneration by marrow. J Orthop Res, 1996; 14(1): 85-93.

4. Patricia A, Zuk AP, Zhu M, et al. Human adipose tissue is a source of multipotent stem cells. Mol Biol Cell, 2002; 13(12): 4279-95.

5. Anker PS, Scherjon SA, Kleijburg-van der Keur C, et al. Amniotic fluid as a novel source of mesenchymal stem cells for therapeutic transplantation. Blood, 2003; 102(4): 1548-49

6. Campagnoli C, Roberts IAG, Kumar S, et al. Identification of mesenchymal stem progenitor cells in human first-trimester fetal blood, liver, and bone marrow. Blood, 2001; 98(8): 2396-02.

7. Nakahara H, Dennis JE, Bruder SP, et al. In vitro differentiation of bone and hypertrophic cartilage from periosteal-derived cells. Exp Cell Res, 1991; 195(2): 492-503. 8. Seo BM, Miura M, Gronthos S, et al. Investigation of multipotent postnatal stem cells from human periodontal ligament. Lancet, 2004; 364(9429): 149-55.

9. Gronthos S, Mankani M, Brahmin J, et al. Postnatal human dental pulp stem cells in vitro and in vivo. Proc Natl Acad Sci USA 2000; 97: 13625-30.
10. Gronthos S, Mankani M, Brahmin J, et al. Stem cell properties of human dental pulp stem cells. J Dent Res, 2002, 81: 531-35.

11. Shi, S, Gronthos, S. Perivascular niché of postnatal mesenchymal stem cells in human bone marrow and dental pulp. Journal of Bone and Mineral Research 2003, 18 (4): 696.

12. Miura M, Gronthos S, Zhao M, et al. SHED: Stem cells from human exfoliated deciduous teeth. Proc Natl Acad Sci USA, 2003; 100 (10): 5807-12.

13. Hilfiker A., Kasper C., Hass R., Haverich A. Mesenchymal stem cells and progenitor cells in connective tissue engineering and regenerative medicine: is there a future for transplantation? Langenbecks Arch Surg, 2011, 396, 489-497.

14. Méndez-Ferrer S, Michurina TV, Ferraro F, Mazloom AR, Macarthur BD, Lira SA, Scadden DT, Ma'ayan A., Enikolopov GN, Frenette PS. Mesenchymal and haematopoietic stem cells form a unique bone marrow niche. Nature, 2010, 466, 829-834.

15. Hass R, Kasper C, Böhm S, Jacobs R. Different populations and sources of human mesenchymal stem cells (MSC): A comparison of adult and neonatal tissue-derived MSC. Cell Commun Signal, 2011, 9, 1-14.

16. Sotiropoulou P, Perez S, Salagianni M, et al. Characterization of the optimal culture conditions for clinical scale production of human mesenchymal stem cells. Stem cells (Dayton, Ohio), 2006; 24(2): 462-71.

17. Sypniewska G, Xu XF, Hager A, et al. Effects of age, obesity and growth-hormone on adipogenic activity in human plasma. Int J Obes 1987; 11: 263-73.

18. Dictus C, Tronnier V, Unterberg A, et al. Comparative analysis of in vitro conditions for rat adult neural progenitor cells. J Neurosci Methods 2007; 161: 250-58.

19. Mannello F, Tonti G. Concise review: no breakthroughs for human mesenchymal and embryonic stem cell culture: conditioned medium, feeder layer, or feeder-free; medium with fetal calf serum, human serum, or enriched plasma; serumfree, serum replacement nonconditioned medium, or ad hoc formula? All that glitters is not gold!. Stem cells (Dayton, Ohio). 2007; 25(7): 1603-9. Available at: http://www.ncbi.nlm.nih.gov/pubmed/17395775. Accessed June 30, 2011

20. Huang AH, Chen YK, Chan AW, et al. Isolation and characterization of human dental pulp stem/stromal cells from nonextracted crown-fractured teeth requiring root canal therapy. J Endod 2009 May; 35(5): 673-81

21. Gronthos S, Arthur A, Bartold PM, et al. A method to isolate and culture expand human dental pulp stem cells. Methods Mol Biol. 2011; 698: 107-21. doi: 10.1007/978-1-60761-999-4_9.

22. Ishkitiev N, Yaegaki K, Imai T, et al. High-purity hepatic lineage differentiated from dental pulp stem cells in serum-free medium. J Endod. $2012 \mathrm{Apr}$; 38(4): 475-80. doi: 10.1016/j.joen.2011.12.011. Epub 2012 Ja.

23. Suchánek J, Soukup T, Ivančaková R, et al. Human dental pulp stem cells - isolation and long term cultivation. Acta Medica (Hradec Králové). 2007; 50(3): 195-201.

24. Zheng X, Baker H, Hancock WS, et al. Proteomic analysis for the assessment of different lots of fetal bovine serum as a raw material for cell culture. Part IV. Application of proteomics to the manufacture of biological drugs. Biotechnol Prog 2006; 22: 1294-300.

25. Gronthos S, Cherman N, Robey P, et al. Human dental pulp stem cells. Adult Stem Cells. Totowa, New Jersey: Humana Press, 2004: 37-51, 101-49.

26. Gronthos S, Brahim J, Li W, et al. Stem cell properties of human dental pulp stem cells. J Dent Res. 2002; 81 (8): 531-35.

27. van den Bos C, Mosca JD, Winkles J, et al. Human mesenchymal stem cells respond to fibroblast growth factors. Hum Cell 1997; 10: 45-50.

28. Tsutsumi S, Shimazu A, Miyazaki K, et al. Retention of multilineage differentiation potential of mesenchymal cells during proliferation in response to FGF. Biochem Biophys Res Commun 2001; 288: 413-19.

29. Sotiropoulou P, Perez S, Salagianni M, et al. Characterization of the optimal culture conditions for clinical scale production of human mesenchymal stem cells. Stem cells (Dayton, Ohio). 2006; 24(2): 462-71. Available at: http://www.ncbi .nlm.nih.gov/pubmed/16109759. Accessed March 3, 2012.

30. Bernardo ME, et al. Ex vivo expansion of mesenchymal stromal cells. Best Pract Res Clin Haematol, 2011, 24, 73-81.

31. Hatlapatka, T., et al. Optimization of culture conditions for the expansion of umbilical cord-derived mesenchymal stem or stromal cell-like cells using xenofree culture conditions. Tissue Eng Part C Methods, 2011, 17, 485-493.

32. Suchánek J, Soukup T, Víšek B, et al. Dental pulp stem cells and their characterization. Biomedical papers of the Medical Faculty of the University Palacký, Olomouc, Czechoslovakia. 2009; 153(1): 31-5. Available at: http://www.ncbi .nlm.nih.gov/pubmed/19365523.

Received: 30/07/2013

Accepted in revised form: 04/11/2013

\section{Corresponding author:}

Jakub Suchánek, Dept. of Dentistry, University Hospital Hradec Králové, Sokolská 581, 50005 Hradec Králové, Czech Republic; e-mail: suchanekj@1fhk.cuni.cz 